\title{
Factors Influencing Teleworking Productivity - a Natural Experiment during the COVID-19 Pandemic
}

\author{
Xiao Shi ${ }^{1}$ (D), Anne Vernez Moudon ${ }^{1}$ (D), Brian H. Y. Lee, ${ }^{2}$ Qing Shen ${ }^{1}$ (D), Xuegang (Jeff) Ban ${ }^{3}$ (D) \\ ${ }^{1}$ Department of Urban Design and Planning, University of Washington, ${ }^{2}$ Puget Sound Regional Council, ${ }^{3}$ Department of Civil \& Environmental Engineering, \\ University of Washington \\ Keywords: commute trip reduction, work from home, teleworking, productivity, covid-19, transportation demand management \\ https://doi.org/10.32866/001c.18195
}

\section{Findings}

\begin{abstract}
Of 2174 surveyed adults who were teleworking following the implementation of a Covid-19 work-from-home policy, $23.8 \%$ reported an increase in productivity, $37.6 \%$ no change, and $38.6 \%$ a decrease in productivity compared to working at their prior workplace. After controlling for feelings of depression and anxiety likely caused by pandemic-related circumstances, the socioeconomic characteristics associated with no change or an increase in productivity after shifting to teleworking included being older; not employed in higher education; having lower education attainment; and not living with children. Respondents with longer commute trips in single-occupancy vehicles prior to teleworking were more likely to be more productive but those with longer commute by walking were not. Lifestyle changes associated with increased productivity included better sleep quality, spending less time on social media, but more time on personal hobbies.
\end{abstract}

\section{RESEARCH QUESTIONS}

The Covid-19 pandemic has rekindled interest in teleworking as a potentially promising work arrangement. A preferred protective option as long as the virus cannot be contained (Baert et al. 2020), teleworking can also serve in the long term as a viable strategy for Transportation Demand Management (TDM) and specifically for Commuting Trip Reduction (CTR) (Hook et al. 2020). While the effects of CTR on transportation efficiency and environmental benefits of CTR are well known, those of working from home (WFH) on work productivity remain under-researched (Kazekami 2020; Nakrošiené, Bučiūniené, and Goštautaitè 2019; Neufeld and Fang 2005; Ruth and Chaudhry 2008; Aboelmaged and El Subbaugh 2012; Pigini and Staffolani 2019). This study took advantage of a recent WFH policy, which acted as a natural experiment to learn about personal factors associated with "successfully" WFH. A survey administered around Seattle, Washington, aimed to identify the characteristics of people more suited to WFH so that a portion of the Covid-19 WFH population might continue to do so after Covid-19, which would contribute to TDM and CTR outcomes while maintaining workforce productivity (Organisation for Economic Cooperation and Development (OECD) 2020). Specific questions focused on:

1. The socioeconomic characteristics (SES) and commuting patterns of the population that continued to be productive during Covid-19 WFH 
2. The lifestyle changes that helped the WFH population continue to be productive while teleworking

\section{METHODS AND DATA}

\section{Study and Survey Design}

We conducted the survey between April and June 2020 in the four counties of the central Puget Sound (Seattle) region, Washington, and asked participants about changes in their work productivity, daily routines, and mental wellbeing since WFH during Covid-19. We used convenience sampling, with a target population of adults older than 18 living in the region's four counties. The survey was managed online and distributed through professional email lists of public agencies, non-government organizations, universities and colleges, as well as other public community groups. There was no financial incentive for participation. We obtained responses from 2174 adults from $83 \%$ of the ZIP Codes in the four counties, who had shifted from working away to WFH since Covid-19. Compared to central Puget Sound region general population, $69 \%$ of our participants had a household income higher than the region's median; $67 \%$ were female (50\% in the region) and $52 \%$ had graduate degrees or above (32\% in the region) (Table 1). Detailed information on the survey was documented elsewhere (Puget Sound Regional Council 2020). 
Table 1. Characteristics of participants, their SES, prior commute trip patterns, mental wellbeing status, lifestyle changes

since Covid-19 ( $\mathrm{N}=2174)$

\begin{tabular}{|c|c|c|c|c|c|}
\hline & Outcome & & Education & & * \\
\hline Variables & Descriptive Statistics & & High school or 2yr college & $251(11.5 \%)$ & \\
\hline Productivity (outcome) & & & 4yr college & $777(35.7 \%)$ & \\
\hline Less productive & $839(38.6 \%)$ & & Graduate or post graduate & $1129(51.9 \%)$ & \\
\hline No change & $817(37.6 \%)$ & & Not applicable & $17(0.8 \%)$ & \\
\hline \multirow[t]{2}{*}{ More productive } & $518(23.8 \%)$ & & & & \\
\hline & & & Housing status & & * \\
\hline & Domain: SES & & Own & $1411(64.9 \%)$ & \\
\hline Variables & Descriptive Statistics & Sig. ${ }^{1}$ & Rent & $715(32.9 \%)$ & \\
\hline Age & & * & Not applicable & $48(2.2 \%)$ & \\
\hline 18 to 29 & $389(17.9 \%)$ & & & & \\
\hline 30 to 39 & $538(24.7 \%)$ & & Living arrangement & & * \\
\hline 40 to 49 & 455 (20.9\%) & & Partner & $876(40.3 \%)$ & \\
\hline 50 to 59 & $483(22.2 \%)$ & & Live alone & $316(14.5 \%)$ & \\
\hline 60 and above & $306(14.1 \%)$ & & Friends \& relatives & $308(14.2 \%)$ & \\
\hline \multirow[t]{2}{*}{ Not applicable } & $3(0.1 \%)$ & & Children & $619(28.5 \%)$ & \\
\hline & & & Not applicable & $55(2.5 \%)$ & \\
\hline \multicolumn{6}{|l|}{ Gender } \\
\hline Female & 1499 (69.0\%) & & Dog ownership & & \\
\hline Male & $646(29.7 \%)$ & & Yes & $756(34.8 \%)$ & \\
\hline Other & $29(1.3 \%)$ & & No & $1418(65.2 \%)$ & \\
\hline Income & & * & Vehicle ownership & & \\
\hline below $40 \mathrm{k}$ & $145(6.7 \%)$ & & Yes & $2029(93.3 \%)$ & \\
\hline$[40 \mathrm{k}-90 \mathrm{k})$ & $478(22.0 \%)$ & & No & $145(6.7 \%)$ & \\
\hline$[90 \mathrm{k}-150 \mathrm{k})$ & $757(34.8 \%)$ & & & & \\
\hline above $150 \mathrm{k}$ & 735 (33.8\%) & & & al wellbeing & \\
\hline \multirow[t]{2}{*}{ Not applicable } & $59(2.7 \%)$ & & Variables & Descriptive Statistics & Sig. \\
\hline & & & Depression measure & & * \\
\hline Employment & & * & Mean (SD) & $1.45(1.48)$ & \\
\hline Professional & $1178(54.2 \%)$ & & Median [Min, Max] & $1.00[0,6]$ & \\
\hline Student & $249(11.5 \%)$ & & & & \\
\hline Faculty & $122(5.6 \%)$ & & Anxiety measure & & * \\
\hline Staff & 444 (20.4\%) & & Mean (SD) & $4.02(4.14)$ & \\
\hline Business person & $131(6.0 \%)$ & & Median [Min, Max] & $3.00[0,24]$ & \\
\hline Others & $50(2.3 \%)$ & & & & \\
\hline
\end{tabular}

Note 1 - significant in univariate models. 
Table 1 (continued). Characteristics of participants, their SES, prior commute trip patterns, mental wellbeing status,

lifestyle changes since Covid-19( $\mathrm{N}=2174)$

\begin{tabular}{|c|c|c|c|c|c|}
\hline \multicolumn{3}{|c|}{ Domain: lifestyle changes } & \multicolumn{3}{|c|}{ Domain: previous commute trip duration (one-way trip) by mode } \\
\hline Variables & Descriptive Statistics & Sig. & Variables & Descriptive Statistics & Sig. \\
\hline Sleep quality & & * & Walking & & * \\
\hline 1-Decreased a lot & $216(9.9 \%)$ & & 0-do not use & $1603(73.7 \%)$ & \\
\hline 2-Decreased somewhat & $654(30.1 \%)$ & & $1-<15 \min$ & $235(10.8 \%)$ & \\
\hline 3-No change & 820 (37.7\%) & & $2-16$ to $30 \mathrm{~min}$ & $179(8.2 \%)$ & \\
\hline 4-Increased somewhat & $384(17.7 \%)$ & & 3-31 to $45 \mathrm{~min}$ & $80(3.7 \%)$ & \\
\hline 5-Increased a lot & $97(4.5 \%)$ & & $4-45$ to $60 \mathrm{~min}$ & $43(2.0 \%)$ & \\
\hline Not applicable & $3(0.1 \%)$ & & $5->1 \mathrm{hr}$ & $34(1.6 \%)$ & \\
\hline Amount of food consumption & & & Biking & & \\
\hline 1-Decreased a lot & $21(1.0 \%)$ & & 0-do not use & $1877(86.3 \%)$ & \\
\hline 2-Decreased somewhat & $258(11.9 \%)$ & & $1-<15 \min$ & $54(2.5 \%)$ & \\
\hline 3-No change & $1060(48.8 \%)$ & & $2-16$ to $30 \mathrm{~min}$ & $109(5.0 \%)$ & \\
\hline 4-Increased somewhat & $738(33.9 \%)$ & & $3-31$ to $45 \mathrm{~min}$ & $63(2.9 \%)$ & \\
\hline 5-Increased a lot & $97(4.5 \%)$ & & $4-45$ to $60 \mathrm{~min}$ & $46(2.1 \%)$ & \\
\hline Not applicable & $0(0 \%)$ & & $5->1 \mathrm{hr}$ & $25(1.1 \%)$ & \\
\hline Amount of exercise & & * & Transit & & * \\
\hline 1-Decreased a lot & $567(26.1 \%)$ & & 0 -do not use & $1018(46.8 \%)$ & \\
\hline 2-Decreased somewhat & $552(25.4 \%)$ & & $1-<15 \min$ & $92(4.2 \%)$ & \\
\hline 3-No change & $297(13.7 \%)$ & & $2-16$ to $30 \mathrm{~min}$ & $299(13.8 \%)$ & \\
\hline 4-Increased somewhat & $542(24.9 \%)$ & & 3-31 to $45 \mathrm{~min}$ & $297(13.7 \%)$ & \\
\hline 5-Increased a lot & $207(9.5 \%)$ & & $4-45$ to $60 \mathrm{~min}$ & $296(13.6 \%)$ & \\
\hline Not applicable & $9(0.4 \%)$ & & 5->1hr & $172(7.9 \%)$ & \\
\hline Time on social media & & * & Single Occupancy Vehicle (SOV) & & * \\
\hline 1-Decreased a lot & $23(1.1 \%)$ & & 0 - do not use & $946(43.5 \%)$ & \\
\hline 2-Decreased somewhat & $76(3.5 \%)$ & & $1-<15 \min$ & 300 (13.8\%) & \\
\hline 3-No change & $828(38.1 \%)$ & & $2-16$ to $30 \mathrm{~min}$ & 435 (20.0\%) & \\
\hline 4-Increased somewhat & $781(35.9 \%)$ & & 3-31 to $45 \mathrm{~min}$ & $278(12.8 \%)$ & \\
\hline 5-Increased a lot & $293(13.5 \%)$ & & $4-45$ to $60 \mathrm{~min}$ & $146(6.7 \%)$ & \\
\hline Not applicable & $173(8.0 \%)$ & & $5->1 \mathrm{hr}$ & $69(3.2 \%)$ & \\
\hline Time on personal hobby & & * & High Occupancy Vehicle (HOV) & & \\
\hline 1-Decreased a lot & $118(5.4 \%)$ & & 0 - do not use & $1882(86.6 \%)$ & \\
\hline 2-Decreased somewhat & $194(8.9 \%)$ & & $1-<15 \min$ & $62(2.9 \%)$ & \\
\hline 3-No change & 862 (39.7\%) & & $2-16$ to $30 \mathrm{~min}$ & $90(4.1 \%)$ & \\
\hline 4-Increased somewhat & $701(32.2 \%)$ & & 3-31 to $45 \mathrm{~min}$ & $78(3.6 \%)$ & \\
\hline 5 -Increased a lot & $193(8.9 \%)$ & & $4-45$ to $60 \mathrm{~min}$ & $40(1.8 \%)$ & \\
\hline Not applicable & $106(4.9 \%)$ & & $5->1 \mathrm{hr}$ & $22(1.0 \%)$ & \\
\hline
\end{tabular}




\section{Variables}

The unit of analysis was the participant. The outcome of interest was selfreported change in productivity since WFH. Participants were given three options: no change, a decrease or an increase in productivity. Productivity was treated as an ordinal variable with decrease in productivity as the reference. Hypothesized predictors of productivity change came from four domains: socioeconomic status (SES), previous commute trip mode and duration, lifestyle changes (sleep quality, food consumption, amount of exercise, time spent on social media or personal hobby), and mental wellbeing. Mental wellbeing variables served to control for potential effects on people caused by Covid-19 circumstances. To evaluate depression, we used two questions from the Patient Health Questionnaire (PHQ-2, (Kroenke, Spitzer, and Williams 2003): how often participants felt depressed or had little interest in doing things on a 4 -point Likert scale $(0=$ Not at all; $1=$ Several days; $2=$ More than half the days; 3 = Nearly every day). To evaluate anxiety, we used 6 questions from the Brief Symptom Inventory (BSI, (Derogatis and Melisaratos 1983) on a 5 -point Likert scale $(0=$ Not at all, $1=\mathrm{A}$ little bit, $2=$ Moderately, $3=$ Quite a bit, $4=$ Extremely). Depression and anxiety measures were indexed by summing all scaled question results, with higher scores indicating higher levels of perceived depression (range $=0$ to 6 ) or anxiety (range $=0$ to 24 ). The details of the method can be found elsewhere and both measures have been tested for validity in previous studies (Cohen-Cline, Turkheimer, and Duncan 2015; Duncan et al. 2020). Table 1 shows how the variables were coded.

\section{Statistical Analysis}

Partial proportional odds (PPO) models, also referred to as generalized ordered logit models were used in the analysis, which relax the parallel line assumption for variables having different relations with each pair of ordinal outcome groups (Williams 2016). Brant test was used to screen the variables that did not meet the assumption. In PPO models, for variables that met the parallel assumption, one set of coefficients were estimated; while for others, two coefficients corresponding to decrease vs. no change and no change vs. increase were estimated separately. We first tested univariate models for all hypothesized predictors. A full PPO model was then estimated with all the predictors significant in univariate models. A final, reduced model included only the variables that had remained significant in the full model (Table 2, Figure 1). VIF scores showed no issue with collinearity. For each model, we used listwise deletion where only observations with complete information were included.

\section{FINDINGS}

\section{Change in productivity since teleworking}

Of the 2147 survey respondents, $38 \%$ reported being less productive since shifting to WFH; $37.6 \%$ reported having no change; and $23.8 \%$ reported being more productive than prior to teleworking (Table 1). The WFH arrangement, 
Table 2. Association between reported productivity, SES, mental wellbeing, previous commute trip mode and duration, and lifestyle changes $(\mathrm{N}=1846)$

Reduced Model ${ }^{1}$

Dependent Variable: Productivity (decrease [ref.], no change, increase)

\begin{tabular}{|c|c|c|c|c|}
\hline Domains & Predictors & $O R$ & $95 \% \mathrm{Cl}$ & $p$ \\
\hline \multirow[t]{22}{*}{ SES } & Age & & & \\
\hline & - 18 to 29 & 0.48 & $0.33-0.69$ & $<0.001$ \\
\hline & - 30 to 39 & 0.93 & $0.68-1.27$ & 0.655 \\
\hline & - 40 to 49 & 1.10 & $0.79-1.31$ & 0.573 \\
\hline & - 50 to 59 & 1.00 & $0.73-1.37$ & 0.988 \\
\hline & - 60 and above & & Reference & \\
\hline & Employment & & & \\
\hline & - professionals & & Reference & \\
\hline & - student & 0.41 & $0.28-0.59$ & $<0.001$ \\
\hline & - faculty & 0.47 & $0.30-0.72$ & 0.001 \\
\hline & - staff & 0.76 & $0.61-0.95$ & 0.017 \\
\hline & - business person & 0.77 & $0.53-1.12$ & 0.176 \\
\hline & - others & 0.99 & $0.56-1.72$ & 0.961 \\
\hline & Education & & & \\
\hline & - high school or $2 y r$ college & 1.32 & $0.98-1.79$ & 0.072 \\
\hline & - 4yr college & 1.36 & $1.11-1.66$ & 0.003 \\
\hline & - graduate and above & & Reference & \\
\hline & Living arrangement & & & \\
\hline & - partner & & Reference & \\
\hline & - live alone & 0.96 & $0.73-1.25$ & 0.756 \\
\hline & - friends \& relatives & 1.18 & $0.88-1.57$ & 0.263 \\
\hline & - children & 0.63 & $0.50-0.80$ & $<0.001$ \\
\hline \multirow{2}{*}{$\begin{array}{l}\text { Previous Commuting } \\
\text { Trip Mode and Duration }\end{array}$} & Walking & 0.90 & $0.83-0.98$ & 0.022 \\
\hline & sov & 1.14 & $1.07-1.22$ & $<0.001$ \\
\hline \multirow[t]{5}{*}{ Lifestyle Changes } & Sleep quality & 1.19 & $1.08-1.31$ & $<0.001$ \\
\hline & Time on social media & 0.84 & $0.75-0.94$ & 0.002 \\
\hline & Time on personal hobby ${ }^{2}$ & & & \\
\hline & - (Decrease vs. No change) & 1.10 & $0.98-1.22$ & 0.074 \\
\hline & - (No change vs. Increase) & 1.24 & $1.08-1.39$ & 0.001 \\
\hline \multirow[t]{4}{*}{ Mental Wellbeing } & Depression measure & 0.83 & $0.79-0.91$ & $<0.001$ \\
\hline & Anxiety measure ${ }^{2}$ & & & \\
\hline & - (Decrease vs. No change) & 1.00 & $0.97-1.03$ & 0.855 \\
\hline & - (No change vs. Increase) & 1.05 & $1.02-1.09$ & 0.001 \\
\hline Log-likelihood & \multicolumn{4}{|c|}{-1825.94} \\
\hline
\end{tabular}

Note 1 - This reduced PPO model excluded variables that were not significant in the full model (income, house ownership, transit trip duration, amount of exercise)

Note 2 - In the PPO model, variables violating the parallel line assumption (time on personal hobby and anxiety measure) were estimated with coefficients for each pair of ordinal outcome groups. 


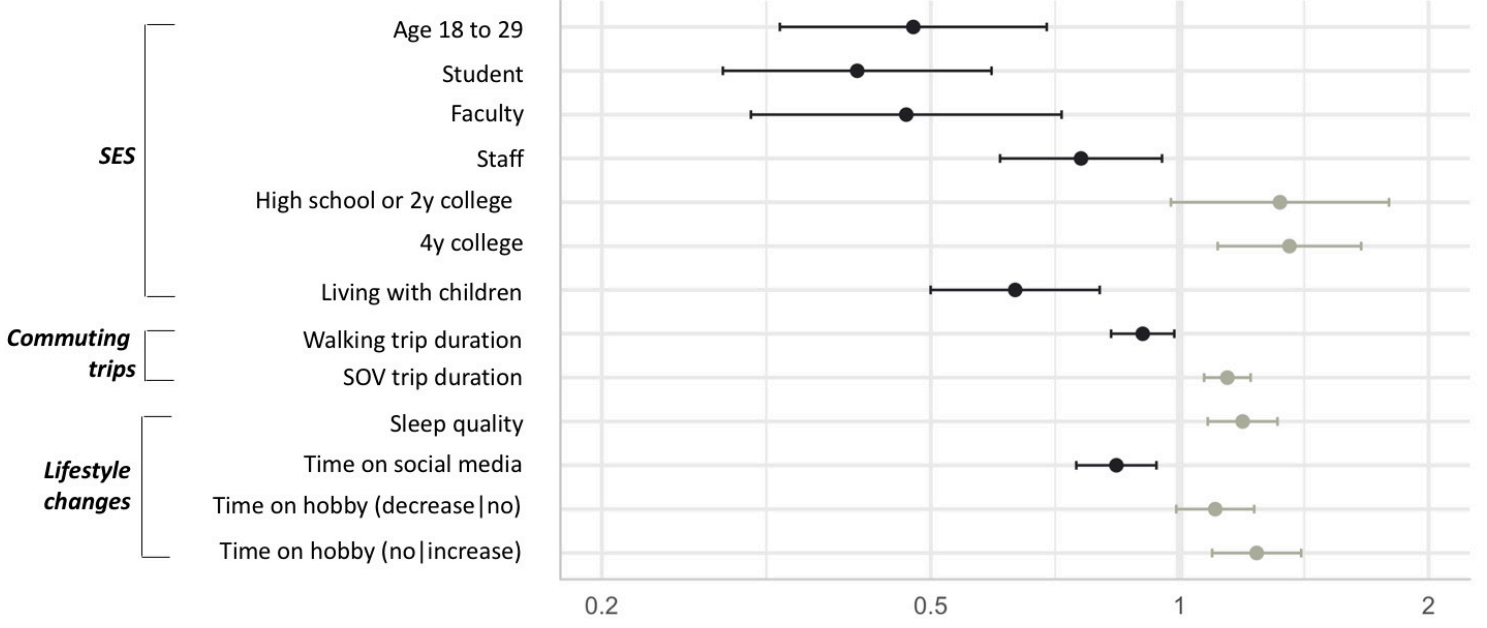

Figure 1. Odds ratio and $95 \%$ confidence interval of factors associated with no change or increase in productivity

which respondents worked under between April and June 2020 mandated telecommuting every workday, which is a more restricted condition than most WFH where workers may have more choices regarding the number of days and times of teleworking. All these conditions may affect the productivity of WFH.

\section{Domains of influence on teleworking productivity}

\section{SES}

After controlling for mental status, people aged 30 and above had a higher probability of reporting no change or an increase in productivity after shifting to teleworking. Respondents not living with children, and therefore less likely to experience unexpected interruptions, were more likely to report no change or increase in productivity. Those in higher education, including students, faculty, and staff, tended to report being less productive. Those with higher educational attainment (having a graduate degree and above) also tended to report being less productive. This is likely due to the nature of academic work (e.g. teaching and knowledge production), which often relies on specific equipment and facilities not available at home, as well as on in-person communications (Carlino and Kerr 2014; McFadyen and Albert A. Cannella 2016). The population segments associated with no change or increase in productivity are potential targets for future long-term teleworking arrangements. Conversely, those who reported a decrease in productivity after shifting to WFH could benefit from additional support from family, employer, and community if continuing to WHF.

\section{PREVIOUS COMMUTE MODE AND DURATION}

Participants with longer Single Occupant Vehicle (SOV) trips before having the WFH had a higher probability of reporting no change or an increase in productivity after shifting to teleworking. In contrast, those with longer walking trips, had a higher probability of reporting a decrease in productivity. 
This is likely because the benefits of eliminating commuting time do not balance off the physical and mental benefits brought by walking to and from work, as suggested by prior studies (Páez and Whalen 2010; Whalen, Páez, and Carrasco 2013).

\section{LIFESTYLE CHANGES}

Sleep quality has long been associated with work productivity and quality of life (Kucharczyk, Morgan, and Hall 2012). We found similar positive relationship between sleep quality and reported productivity after shifting to teleworking. More time spent on social media was linked to a decrease in productivity. This was consistent with the negative effects of the distractions, physical discomfort, and negative emotions associated with social media use as reported in previous studies of workplace and office settings (Priyadarshini et al. 2020; Vithayathil, Dadgar, and Osiri 2020). On the other hand, more time spent on personal hobbies, was linked to maintaining the same level of productivity, or to increasing productivity. This suggested that engaging in nonwork related activities helped compensate for the demands of continuous work (Eschleman et al. 2014).

\section{ACKNOWLEDGMENTS}

This work has been funded by the US Department of Transportation's University Transportation Center program through the Pacific Northwest Regional University Transportation Center (PacTrans) and Puget Sound Regional Council (PSRC). The authors would like to thank PacTrans and PSRC for their support. Views expressed in the paper do not represent those of the sponsors and the authors are responsible for all errors that may exist. 


\section{REFERENCES}

Aboelmaged, Mohamed Gamal, and Shawky Mohamed El Subbaugh. 2012. "Factors Influencing Perceived Productivity of Egyptian Teleworkers: An Empirical Study.” Measuring Business Excellence.

Baert, Stijn, Louis Lippens, Eline Moens, Johannes Weytjens, and Philippe Sterkens. 2020. “The Covid-19 Crisis and Telework: A Research Survey on Experiences, Expectations and Hopes.” SSRN Scholarly Paper ID 3596696. Rochester, NY: Social Science Research Network. https://papers.ssrn.com/abstract=3596696.

Carlino, Gerald, and William R Kerr. 2014. "Agglomeration and Innovation.” Working Paper 20367. Working Paper Series. National Bureau of Economic Research. https://doi.org/10.3386/ w20367.

Cohen-Cline, Hannah, Eric Turkheimer, and Glen E Duncan. 2015. "Access to Green Space, Physical Activity and Mental Health: A Twin Study." Journal of Epidemiology and Community Health 69 (6): 523-29. https://doi.org/10.1136/jech-2014-204667.

Derogatis, Leonard R., and Nick Melisaratos. 1983. "The Brief Symptom Inventory: An Introductory Report.” Psychological Medicine 13 (3): 595-605.

Duncan, Glen E., Ally R. Avery, Edmund Seto, and Siny Tsang. 2020. "Perceived Change in Physical Activity Levels and Mental Health during COVID-19: Findings among Adult Twin Pairs." Edited by Michio Murakami. PLOS ONE 15 (8): e0237695. https://doi.org/10.1371/ journal.pone.0237695.

Eschleman, Kevin J., Jamie Madsen, Gene Alarcon, and Alex Barelka. 2014. "Benefiting from Creative Activity: The Positive Relationships between Creative Activity, Recovery Experiences, and Performance-Related Outcomes." Journal of Occupational and Organizational Psychology 87 (3): 579-98. https://doi.org/10.1111/joop.12064.

Hook, Andrew, Victor Court, Benjamin K Sovacool, and Steve Sorrell. 2020. "A Systematic Review of the Energy and Climate Impacts of Teleworking." Environmental Research Letters 15 (9): 093003. https://doi.org/10.1088/1748-9326/ab8a84.

Kazekami, Sachiko. 2020. "Mechanisms to Improve Labor Productivity by Performing Telework." Telecommunications Policy 44 (2): 101868.

Kroenke, Kurt, Robert L. Spitzer, and Janet BW Williams. 2003. "The Patient Health Questionnaire-2: Validity of a Two-Item Depression Screener.” Medical Care, 1284-92.

Kucharczyk, Erica R., Kevin Morgan, and Andrew P. Hall. 2012. “The Occupational Impact of Sleep Quality and Insomnia Symptoms.” Sleep Medicine Reviews 16 (6): 547-59. https://doi.org/ $\underline{10.1016 / j . s m r v .2012 .01 .005}$.

McFadyen, M. Ann, and Jr Albert A. Cannella. 2016. "Knowledge Creation and the Location of University Research Scientists' Interpersonal Exchange Relations: Within and beyond the University:" Strategic Organization, August. https://doi.org/10.1177/1476127005052207.

Nakrošienè, Audronè, Ilona Bučiūnienè, and Bernadeta Goštautaitè. 2019. "Working from Home: Characteristics and Outcomes of Telework." International Journal of Manpower 40 (1): 87-101. https://doi.org/10.1108/IJM-07-2017-0172.

Neufeld, Derrick J., and Yulin Fang. 2005. "Individual, Social and Situational Determinants of Telecommuter Productivity." Information Ev Management 42 (7): 1037-49.

Organisation for Economic Co-operation and Development (OECD). 2020. "Productivity Gains from Teleworking in the Post COVID-19 Era: How Can Public Policies Make It Happen?” 
Páez, Antonio, and Kate Whalen. 2010. "Enjoyment of Commute: A Comparison of Different Transportation Modes." Transportation Research Part A: Policy and Practice 44 (7): 537-49. https://doi.org/10.1016/j.tra.2010.04.003.

Pigini, Claudia, and Stefano Staffolani. 2019. "Teleworkers in Italy: Who Are They? Do They Make More?” International Journal of Manpower.

Priyadarshini, Chetna, Ritesh Kumar Dubey, Y. L. N. Kumar, and Rajneesh Ranjan Jha. 2020. "Impact of a Social Media Addiction on Employees' Wellbeing and Work Productivity." The Qualitative Report 25 (1): 181-96.

Puget Sound Regional Council. 2020. “COVID-19 Mobility Survey.” October 5, 2020. https://www.psrc.org/covid-19-mobility-survey.

Ruth, Stephen, and Imran Chaudhry. 2008. "Telework: A Productivity Paradox?” IEEE Internet Computing 12 (6): 87-90.

Vithayathil, Joseph, Majid Dadgar, and J. Kalu Osiri. 2020. "Does Social Media Use at Work Lower Productivity?” International Journal of Information Technology and Management 19 (1): 47-67. https://doi.org/10.1504/IJITM.2020.104504.

Whalen, Kate E., Antonio Páez, and Juan A. Carrasco. 2013. "Mode Choice of University Students Commuting to School and the Role of Active Travel." Journal of Transport Geography 31 (July): 132-42. https://doi.org/10.1016/j.jtrangeo.2013.06.008.

Williams, Richard. 2016. "Understanding and Interpreting Generalized Ordered Logit Models." The Journal of Mathematical Sociology 40 (1): 7-20. 